\title{
Infection Control in Labor and Delivery Room, Learning from the Small Hospital Based Project
}

\author{
Savera Aziz Ali ${ }^{1}$ and Sumera Aziz Ali* \\ ${ }^{1}$ School of Nursing and Midwifery Aga Khan Hospital, Pakistan \\ ${ }^{2}$ Department of Community Health Sciences, Aga Khan University Hospital, Pakistan
}

Submission: January 04, 2017; Published: February 01, 2017

*Corresponding author: Sumera Ali, Department of Community Health Sciences, Aga Khan University Hospital, Karachi, Pakistan, Tel: +92 213486 4837; Email: sumera.ali@aku.edu

\begin{abstract}
Background: It has been estimated that around $36 \%$ of the neonatal deaths occur due to infection in the lower and middle income countries. Infection control is a more substantial area of concern, particularly in Labor and delivery room. Multiple factors can cause infection in the labor room, therefore it is important to assess various factors of maternal and neonatal infection. Hence we explored multiple factors through this project and developed the action plan to address those factors effectively.
\end{abstract}

Methods: During our Leadership and Management course, we conducted a project in Labor room pertaining to a prevalent issue. The whole process from identification of the issue to the resolution was supposed to be in the light of leadership and management concepts. After a thorough analysis and discussion, an action plan was formulated considering the resources, audience, facilities and time required for implementation and evaluation. Every step was mentioned in the action plan for identification of issue till the evaluation of the project.

Findings: Factors of infection were grouped under six broad headings including staff, environment, practices, equipment, factors related to patient and others. These were diagrammatically represented through "Fishbone" Diagram

Conclusion: Infection is a common issue in the hospital setting and we tried to assess the factors of infection in the labor room. We identified multiple factors of infection and tried to address those factors by developing a simple action plan. We found that infection can be controlled by taking very simple precautionary measures without incurring a lot of cost.

Keywords: Labor room; Infection; Factors; Action plan

\section{Introduction}

Mothers and neonates are vulnerable to get infections from the surrounding environment of the Hospital [1]. The chances of infection increases, if the precautions are not taken appropriately, especially by nursing staff who is the prime person, responsible for taking care of neonates in the Hospital. Infection control is a more substantial area of concern in Labor and delivery room because these neonates do not adapt to their surroundings immediately after they come out of the womb of mothers. In addition to this, mothers might be exposed to infection due to multiple examinations by health care providers during the process of labor [2]. Moreover, in lower middle income countries, neonatal deaths are due to infections acquired at home or in the hospital and around $36 \%$ of the neonatal deaths occur due to infection [35]. Healthcare professionals always aim to preserve the maternal and newborn health, but sometimes little negligence can put their health at risk which should not be overlooked. Multiple factors can cause infection in the labor room, therefore it is important to assess various factors of maternal and neonatal infection. Hence we explored multiple factors through this project and developed the action plan to address those factors effectively.

\section{Overview of the project}

During our Leadership and Management course, we had to carry out a project in Labor room pertaining to a prevalent issue. The whole process from identification of the issue of the resolution was supposed to be in the light of leadership and management concepts [6]. Amongst multiple issues that were encountered in Labor room, we selected "infection control" as an issue for our project. We carried out a systematic process to collect data by using questionnaire andobservations. A questionnaire was developed after doing literature search. The target audience was 
the nursing staff in the labor room. Through this questionnaire and observation, it was identified that several factors could cause infection. These factors and their cause and effect relationships were grouped under six broad headings including staff, environment, practices, equipment, factors related to patient and others $[7,8]$. For example, staff related factors included lack of awareness and sensitization about the causes of infection. Similarly with respect to equipment in the labor room, warmers were not found to be disinfected properly according to the hospital infection control policy. Likewise patient related factors included increased age, high parity and history of additional co-morbids. This was diagrammatically represented through "Fishbone" Diagram (Figure 1). Fishbone method was selected because it is the most comprehensive way of analyzing complex problems and identifying its causes and effects. It is a type of method which sort out ideas into useful categories and also help to identify the root causes of any problem [9].

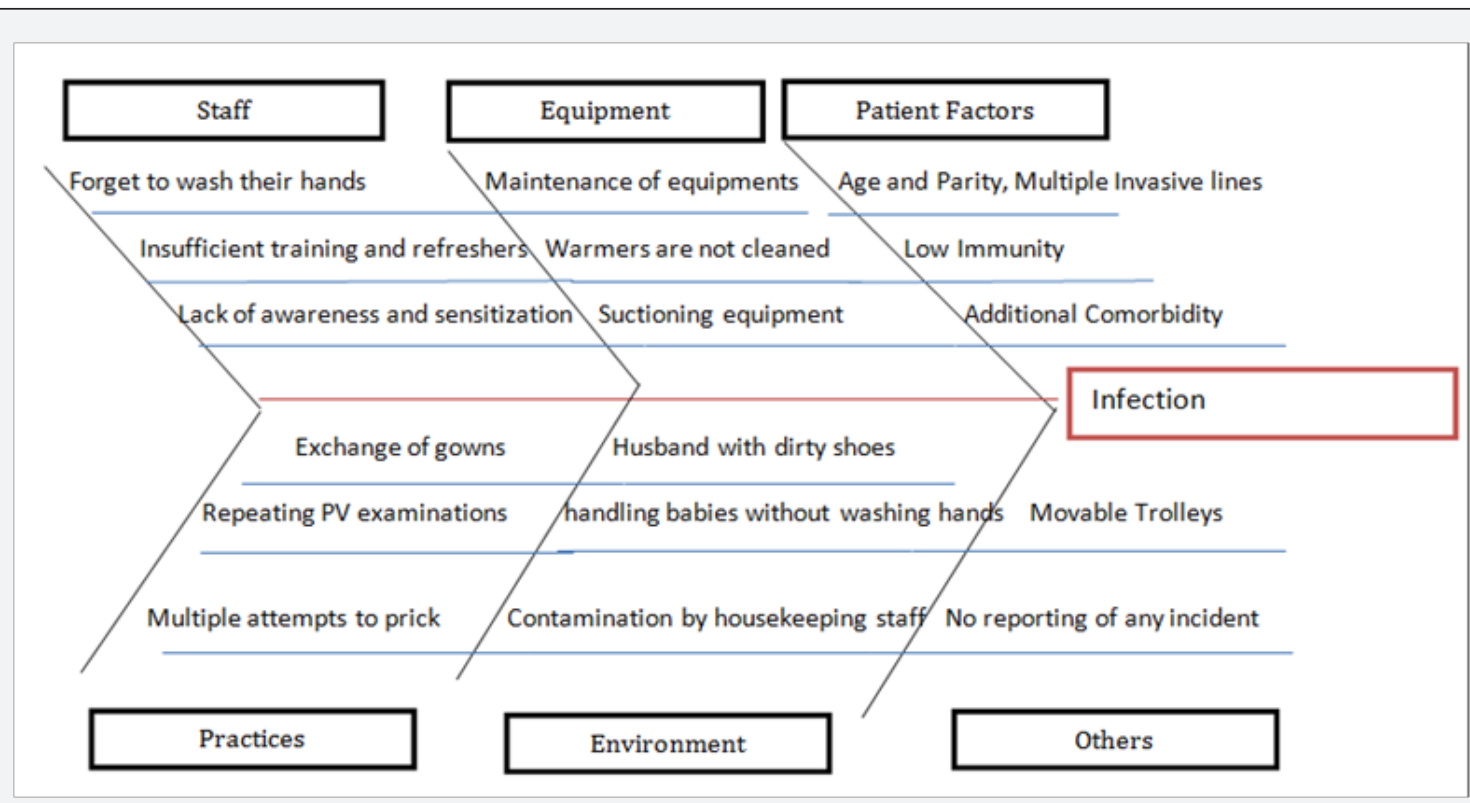

Figure 1: Fish Bone Diagram Infection control in labor and delivery room.

\section{Development of action plan}

After a thorough analysis and discussion, an action plan was formulated considering the resources, audience, facilities and time required for implementation and evaluation. Every step was mentioned in the action plan for identification of issue till the evaluation of the project. A multimodal Interventional approach was planned, including visual and verbal reminders, educational initiatives like educational and motivational sessions for staff through videos. Moreover, action plan also included reviewing different policies with staff and providing pamphlets to each staff highlighting common and important preventive measures to control the infection. These interventions would cater the principle of staff development by building the capacity of staff and by improving their knowledge regarding infection control. It is known fact that in the hospital premises, the chances of infection are always possible; therefore precautionary measures should be taken to avoid the sudden rise in infection [10]. Moreover, problem solving principle can be used to resolve this issue, which is a rational-logical thought process, helping to resolve problems successfully using several incidents of decision making $[11,12]$. For problem solving process, different approaches were identified through brainstorming and literature review of the possible solutions by involving various experts. Furthermore, multiple people can share their ideas and opinions therefore sometimes there could be conflict between different team members, which need to be resolved through the principal of conflict management [13].

\section{Implementation of action plan}

We implemented the action plan in the labor room on the basis of different management principles. All interventions were done as planned and mentioned in the action plan, except a few modifications. We showed the videos of hand washing and suctioning techniques to the nursing staff. Moreover, we also tried to negotiate with the management and administrative staff to change the suctioning bottles after every 24 hours, as mentioned in the infection control policy. We also reviewed different skills with staff, for example IV (Intravenous) canulation, suctioning, Foleys catheterization and infection control policy. In addition to this, the session also consisted of suctioning skill demonstration, which was performed by student nurse with particular emphasis on infection control. Apart from this, we also reinforced the management staff that they should not allow the attendants to enter the labor room with dirty shoes. The whole session was successful, which was reflected by the staff's increased participation during the session 
and positive feedback from the staff at the end of the session. Additionally, we provided pamphlets of infection control. We also gave a brief presentation to reinforce and motivate nursing staff regarding infection prevention practices. However, due to time limitation, we could not cater all the staff, therefore we provided the presentation to receptor so that she could circulate that presentation among staff for their reference. In addition to this, we also pasted the flyers on the notice board to remind the staff whenever needed. Finally, evaluation of nursing staff was done to assess their learning through sessions.

\section{Challenges of the project}

Challenges are unavoidable in any project and one should take those challenges as an opportunity to move forward. The implementation of the proposed action plan was itself a challenge as it required human, financial and time resources. The second most important challenge was the budget, as this project was not funded therefore we had to manage the resources cost effectively within our limited budget. For instance, we recycled the used sheets to make the flash cards, instead of buying the new ones. Another challenge was to gather the staff at a time during the clinic hours for showing them videos and presentation. To overcome this issue, we intervened several times in small groups and it entirely depended on the availability of staff and sometimes we had to utilize shift changing times and break times of the staff as well. Apart from this, we encountered another great challenge of arranging multimedia. Moreover, we had to carry out this project during clinical hours, but we had to utilize our theory hours to meet with a preceptor to discuss the progress of the project.

Our evaluation comprised of ongoing monitoring along with formative feedback from the prospector which indicated the need of further modification in the plan and the success of the project. It also comprised of a summative evaluation as a final step of the problem solving process to identify whether our implementation program proved to be successful. We can say that our project might be a minor contribution towards infection prevention in Labor room, however, we could not measure that change quantitatively due to lack of time and strict deadline. In addition, we also made observations by spot checks to assess staff's practices and we found improvement in their practices.

\section{Conclusion}

Infection is a common issue in the hospital setting and we tried to assess the factors of infection in the labor room. We identified multiple factors of infection and tried to address those factors through a simple action plan. We found that infection can be controlled by taking very simple precautionary measures without incurring a lot of cost. This project was a great learning for us and it developed our organization and communication skills too. Moreover, we also learned how to make and implement an action plan to prevent the occurrence of any bad outcome very effectively. Apart from this, we also learned how to handle such large group efficiently, especially by maintaining their interest in the session. Our group got great support from all the staff and our clinical faculty throughout our project. Their encouragement and support were vital in the success of this project.

\section{References}

1. Ahmed AAM (2015) Assessment of measurements of infection control in the Labor Room at Omdurman Maternity Hospital in 2014-2015: Alzaeim Alazhari University.

2. Chan GJ, Baqui AH, Modak JK, Murillo-Chaves A, Mahmud AA, et al. (2013) Early-onset neonatal sepsis in Dhaka, Bangladesh: risk associated with maternal bacterial colonisation and chorioamnionitis. Trop Med Int Health 18(9): 1057-1064.

3. Black RE, Cousens S, Johnson HL, Lawn JE, Rudan I, et al. (2010) Global, regional, and national causes of child mortality in 2008: a systematic analysis. Lancet 375(9730): 1969-1987.

4. Baqui AH, Darmstadt GL, Williams EK, Kumar V, Kiran TU, et al. (2006) Rates, timing and causes of neonatal deaths in rural India: implications for neonatal health programmes. Bull World Health Organ 84(9): 706713.

5. Ayaz A, Saleem S (2010) Neonatal mortality and prevalence of practices for newborn care in a squatter settlement of Karachi, Pakistan: a crosssectional study. PLoS On 5 (11): e13783.

6. Huber D (2013) Leadership and nursing care management ( $5^{\text {th }}$ edn). Elsevier Health Sciences.

7. Sarah Saleem, Elizabeth M McClure, Janet Moore, Samina Iqbal, Syed Hasan Ala, et al. (2014) Adverse neonatal and maternal outcomes in Pakistani tertiary care hospitals: A prospective, observational study. Elective Medicine Journal 2(2): 40-46.

8. Ofili AN, Okojie OH (2005) Assessment of the role of traditional birth attendants in maternal health care in Oredo Local Government Area, Edo State, Nigeria. Journal of Community Medicine and Primary Health Care 17(1): 55-60.

9. Bjørn Andersen, Tom Fagerhaug (2006) Root cause analysis: simplified tools and techniques. ASQ Quality Press.

10. Dutcher K, Lederman ER, Brodine S, Patel S (2013) Impact of the 2013 Revised Centers for Disease Control and Prevention Central Lineassociated Bloodstream Infection (CLABSI) Surveillance Definition on Inpatient Hospital CLABSI Rates: Is It Enough?. Infection control and Hosp Epidemiol 34(9): 999-1001.

11. Nelson LM (2013) 4 Collaborative I Problem Solving. Instructionaldesign theories and models: A new paradigm of instructional theory $2: 241$.

12. Marquis BL, Huston CJ (2009) Leadership roles and management functions in nursing: Theory and application. Lippincott Williams \& Wilkins.

13. Lederach J (2015) Little Book of Conflict Transformation: Clear Articulation of the Guiding Principles by a Pioneer in the field. Skyhorse Publishing, Inc. 
This work is licensed under Creative Commons Attribution 4.0 License DOI:10.19080/GJPPS.2017.01.555555

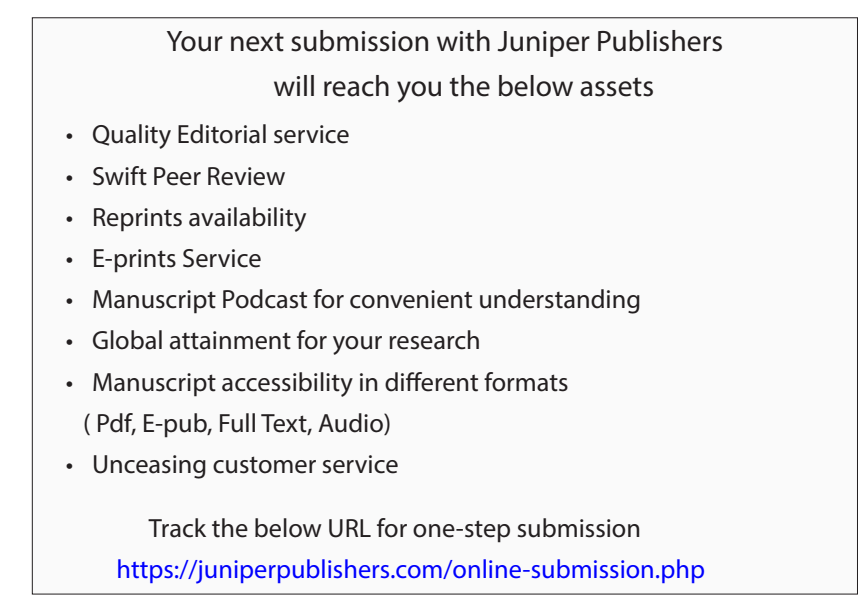

